\title{
The Impact of Summer Camp on Social Skills for Children with Autism Spectrum Disorder
}

\author{
Dr. Amal Ibrahim* \\ Department of Counseling and Special Education, \\ School of Educational Science, the University of Jordan \\ Queen Rania Street, Al Jubeiha, 11942, Amman Jordan \\ Dr. Kathleen A Cronin \\ A Program Specialist for Saddleback Unified School District in Mission Viejo, California, USA.
}

\begin{abstract}
This study examined specific social skills that children with Autism Spectrum Disorder need to improve in their life. This quantitative study obtained data from 40 parents who have children or youth with ASD who participated in a one week day camp. A modified version of the Autism Social Skills Profile (ASSP) was given three times to determine if children and youth with ASD made improvements in social skills after participating in the one week day camp. Survey 1 was distributed before the beginning of camp, survey 2 was given at the end of camp, and survey 3 was given eight weeks post camp. This study reported statistically significant differences when the five domains included in social skills (communication, reciprocity, social cognition, initiation, and perspective taking and self-awareness) were analyzed. The time by treatment interaction was statistically significant for the communication, initiation, and reciprocity domains. These results suggest that participants who attended Camp New Amigos showed a positive impact on social skills for children and youth with ASD, as rated by their parents.
\end{abstract}

Keywords: communication, social skills, imitation, social cognition, perspective taking

DOI: $10.7176 / \mathrm{JEP} / 11-17-14$

Publication date:June 30 th 2020

\section{Introduction}

Autism is a Greek word which came from the word "autos," which means self (Sicile-Kira, 2004).Autism Spectrum Disorders (ASD) is a complex neuro-developmental disorder, and is characterized by different levels of impairment in social interaction, and restricted and repetitive behavior, interests, or activities (Maenneret al., 2020).Autism Spectrum Disorders is growing so fast, affecting more children than any other disease (Kellman, 2010). The last two decades show an increase in the prevalence of ASD for several reasons: more awareness from parents, earlier diagnosis, and using different diagnostic criteria that improved case identification (Parneret al., 2012). Autism was first describedby Kanner in 1943. Kanner had worked with 11 children and he noticed that these children had similar characteristics. After five decades of research, understanding of ASD continues to growin the United States and the world, which has led to a broad range of treatments (Wilczynski\& Pollack, 2009).

\subsection{Background and History of ASD}

ASD is a complex neuro-developmental disorder, and is characterized by different levels of impairment in social interaction, verbal and non-verbal communication, and restricted and repetitive behavior before three years of age (Napolioni et al., 2011). The first case of autism appeared in 1800 when a Frenchman named Itard wrote about a 12-year-old boy who had been living in the woods and was raised by wolves. Itard named the boy, Victor. Victor could not use language or communicate with others (Goldstein \&Ozonoff, 2009).Historically, few studies in the United States have examined the prevalence of ASD. Most of the studies were conducted in different countries such as Japan and Sweden. In 2001 a study conducted by the CDC found that 67 in 10,000 children were diagnosed with ASD. In 2009, the ADDM report showed that one in every 110 children age eight years were diagnosed with ASD. The data were collected in 2004 from eight sites and 2006 from 11 sites (CDC, 2009). Kogan and colleagues (2009) reported that 110 in 10000 children in the United States have ASD. The prevalence was estimated from the 2007 National Survey of Children's Health. A child was considered to have ASD if his parents, doctors, or anyone taking care of her/him agreed with that. In 2012 the CDC released the data collected in 2008 from the 14 ADDM sites (Alabama, Arizona, Arkansas, Colorado, Florida, Maryland, Missouri, New Jersey, North Carolina, Pennsylvania, South Carolina, Utah, West Virginia, and Wisconsin). At that time the overall estimated prevalence of ASD was one in 88 (Baio, 2012). The data collected for these children were based on health and special education records of children age eight. Previous studies had shown that by this age most children with ASD had been identified for services (Baio, 2012). One in 54 children have 
been diagnosed with ASD. In fact, ASD is 4 times more common among boys than girls (Maenner et al., 2020).According to estimates from the CDC and the ADDM Network.

Social skills are the ability to communicate, play, start or maintain conversations, request, comment, and share a game or activity with peers (Morrison, Kamps, Garcia, \& Parker, 2001). Children with ASD have difficulties with different social skills such as communication skills, thinking, cognitive tasks, interests, activities, and motor skills (Goldstein, Naglieri, Rzepa, \&Williams, 2012). Children with ASD have difficulty developing relationships with peers and they fail to engage in joint-attention behaviors (Goin\& Myers, 2004). They also have difficulty in requesting, commenting, and sharing a game or activity with peers (Morrison et al., 2001).

Social skills impairment is common for children with autism. These children have difficulty developing relationships with peers and they fail to engage in joint-attention behaviors (Goin \& Myers, 2004). Children with autism also have impairments in communication skills. One study indicated that fifty percent of individuals with ASD have deficits in developed language (Ostryn, Wolfe, \& Rusch, 2008). Some children with autism do not have any functional communication. Echolalia is repeating words in meaningless ways, and children with autism repeat some words because they may have limited comprehension of the meaning (Tsai, 1998). According to Sterponi and Shankey (2013), children with autism resist change in routines and display unusual restricted and repetitive behavior, and motor movements and stereotypes, such as flapping hands, rocking, jumping, etc. (Schall \& McDonough, 2010). Besides these characteristics, there are many secondary characteristics which affect children with autism, including sensory processing difficulties, anxiety disorders, and depression (Schall \& McDonough, 2010).

This study describes the effect of a summer camp program on improving social skills for children and youth with ASD.The history of summer camp in the United States started in the 1860s. It is considered a special kind of play world. The first summer camps had programs and activities such as swimming, jumping rope, sports, hobbies, and games (Kristen-Clark\&Nwokah, 2011), very similar to today's camps.

\subsection{Description of Camp New Amigos}

Camp New Amigos is one-week summer camp program for children and youth with ASD that started in 2010 at New Mexico State University.Purpose of Camp New Amigos (CAN) isto provide campers with different programs to improve social skills, communication skills, and behavior skills, the campers learn skills while having fun. Children and young adults with a diagnosis of ASD between age 5-21 and who are enrolled in a public school program were invited to attend. The camp was staffed with 55 volunteer counselors that included university students, community professionals, and volunteers desiring additional experience working with individuals with ASD. Camp New Amigos was held from 8:30 a.m. to 3:00 p.m. for a week with a total of 33 hours. The camp provided many activities for campers such as arts and crafts, sports, games, swimming, horseback riding, and music. In 2012, archery, with a certified archery instructor, kayaking, and a climbing wall were added. Training was provided for the counselors and the volunteers before the summer camp.. Parents and family members were invited to join the camp staff and counselors for an evening campout/barbecue. The 75 children in the summer camp were divided into 17 groups. Each group had between 4 and 5 participants. Staffing was based on age and needs of the campers. The overall staffing was approximately 2:1 of campers to staff.

\subsection{The Purpose of the Study}

The purpose of the study was to investigate the effects of a one-week summer camp specifically designed for children and youth with ASD in an effort to determine whether the camp structure and activities would improve social skills as rated by the children's parents. The social skills specifically targeted are in the general social domains of communication, reciprocity, social cognition, initiation, perspective taking and self-awareness. This study aimed to answer the research question: Does participation in summer camp activities improve social skills for children and youth with ASD as rated by their parents?

\section{Methods}

This study used a quasi- experimental design that included administration of a pretest followed by a single treatment and concluding with two post-tests (OXOO). The independent variable in this study was the camp and the dependent variables were social skills which included communication, reciprocity, social cognition, initiation, perspective taking and self-awareness.

2.1. Participants.Forty children with ASD participated in this study. Thirty six of the participants were male $(90 \%)$ and four of the participants' children were female $(10 \%)$. 
Table 1. Descriptive Statistics

\begin{tabular}{|c|c|c|}
\hline Demographic Information & $\mathrm{n}$ & $\%$ \\
\hline \multicolumn{3}{|l|}{ Gender } \\
\hline Male & 36 & 90 \\
\hline Female & 4 & 10 \\
\hline \multicolumn{3}{|l|}{ Ethnicity } \\
\hline Caucasia & 7 & 17.5 \\
\hline Hispanic & 32 & 80 \\
\hline Others & 1 & 2.5 \\
\hline \multicolumn{3}{|l|}{ Communication } \\
\hline Verbal & 29 & 77.5 \\
\hline Non verbal & 11 & 22.5 \\
\hline \multicolumn{3}{|l|}{ Living Arrangements } \\
\hline Parents & 36 & 90 \\
\hline Father & 2 & 5 \\
\hline Grandparents & 2 & 5 \\
\hline \multicolumn{3}{|l|}{ School Placement } \\
\hline SPED & 12 & 55 \\
\hline Regular & 15 & 37.5 \\
\hline Home school & 3 & 7.5 \\
\hline \multicolumn{3}{|l|}{ Students' age } \\
\hline $7-11$ & 24 & 60 \\
\hline $12-17$ & 14 & 37.5 \\
\hline $18-21$ & 1 & 2.5 \\
\hline
\end{tabular}

2.2. Procedures. The consent form and survey were sent to 75 caregivers of children and youth with ASD who participatedin the one-week summer day camp program via email. This email was sent approximately one week before camp. Parents were informed that the purpose of the study was to investigate the effects of a one-week summer day ( 7 hours a day) camp specifically designed for children and youth with ASD in an effort to determine whether the camp structure and activities would improve social skills as rated by the children's parents. Directions for completing the survey were included on the cover page.

The consent form included a description of the goals of the study. Through the consent form, parents who were interested were invited to participate in the study by returning the survey to the researcher via email. Parents who did not return the survey were contacted by email to see if they had any questions about the study. Parents were encouraged to contact the researcher regarding completion of the survey.

A total of 47 caregivers completed the first survey, but two participants were excluded because their caregivers indicated that their children were sick and did not attend the entire summer camp. A total of 43 parents completed the second profile within the first week after the summer camp intervention. The last survey was sent about two months after camp to compare the social skills levels at the end of camp with their social skills levels at the beginning of school. Three participants were excluded because their caregivers did not send the third survey. The data was collected three times from the same parents using the same questionnaires between May and August.

2.3. Instrument. The Autism Social Skills Profile (ASSP) is an instrument created to assist in identifying typical social skills deficits as related to three subscales: social reciprocity, social participation/avoidance, and detrimental social behaviors. It provides a comprehensive measure of the social functioning for students with ASD (Bellini, 2008). The ASSP can be completed by a parent, teacher, or any other adult to determine baseline skills and intervention planning. The ASSP was designed for use with children with ASD ages 6 to 17 years old (Bellini \&Hopf, 2007). The ASSP can be used to assist in intervention planning, to identify the specific social skills deficits of children with ASD, and to assist in the measurement of intervention progress (Bellini, 2008). A major advantage of the ASSP and other behavior rating scales is their ability to obtain a variety of qualities and behaviors from a variety of sources in different settings (Elliott, Malecki, \&Demaray, 2001). The ASSP has been modified by the researcher and revised by expertise in special education for the study. The questionnaire was adapted from Bellini's (2008) Autism Social Skills Profile, based on the review of the literature.

The survey was designed to address the following five subcategories of social skills: communication (pragmatics), reciprocity, social cognition, initiation, and perspective taking and self-awareness. The questions in the ASSP have been grouped into the following social skills domains: three items in communication (e.g., maintains the give-and-take of conversations, maintains eye contact during conversations), five items in reciprocity (e.g., takes turns during games and activities, politely asks others to move out of his/her way); three items in social cognition (e.g., compromises during disagreements with 
others, misinterprets the intentions of others); four items in initiation (e.g., invite peers to join activities, requests assistance from others); and four items in perspective taking and self-awareness (e.g., maintains an appropriate distance when interacting with peers, speaks with an appropriate volume in conversations).

The survey presented items using a four point Likert scale where a 4 meant very often or always exhibited the skill or behavior, 3 meant often or typically exhibited the skill or behavior, 2 meant sometimes or occasionally exhibited the skill or behavior, and a 1 meant never or almost never exhibited the skill or behavior. Each participant completed the survey three times.

The researcher used 19 items items which were in Bellini's Autism Social Skills Profile. Some items were excluded because there were many items which were similar in meaning; e.g., asks questions to request information about a person, and asks questions to request information on a topic. Parents needed to evaluate their children three times, and completing a long survey may not have encouraged participants to continue in the research. The survey was reviewed by an autism expert for reliability.

\section{Data Analysis}

Three comparisons were used to analyze the data in this study: pre (Survey 1) to post 1(Survey 2), post 1(Survey 2) to post 2 (Survey 3), and pre (Survey 1) to post 2 (Survey 3). The study used a one-way ANOVA with correlated samples. Only parents who responded to all three surveys were used in the analysis. The study examined all domains (communication, reciprocity, social cognition, initiation, perspective taking and selfawareness) separately, and as combined domains.

\subsection{Results}

The results of the one-way ANOVA revealed there was a statistically significant improvement in social skills for youth and children with ASD who attended the summer day camp program. For the five domains, there were statistically significant improvements in communication skills, initiation skills, and reciprocity skills while there were no statistically significant differences in social cognition skills and perspective taking and self-awareness skills. The overall findings show a statistically significant increase in social skills for the children and youth with ASD who participated in the summer camp program.

3.1.1. Results of combined domains. The average of the total scores of the combined domains for the first survey was 2.3 , for the second survey the average was 2.5 , and for the third survey, the average was 2.4 on the previously described 4.0 scale.

Table 2. Summary of Results of Combined Domains

\begin{tabular}{llll}
\hline Domains & First survey & Second survey & Third survey \\
\hline Communication & 2.3 & 2.5 & 2.4 \\
Reciprocity & 2.6 & 2.8 & 2.7 \\
Social cognition & 2.3 & 2.4 & 2.4 \\
Initiation & 2.1 & 2.3 & 2.3 \\
Perspective taking/self-awareness & 2.2 & 2.3 & 2.3 \\
Combined Domains & 2.3 & 2.5 & 2.4 \\
\hline
\end{tabular}

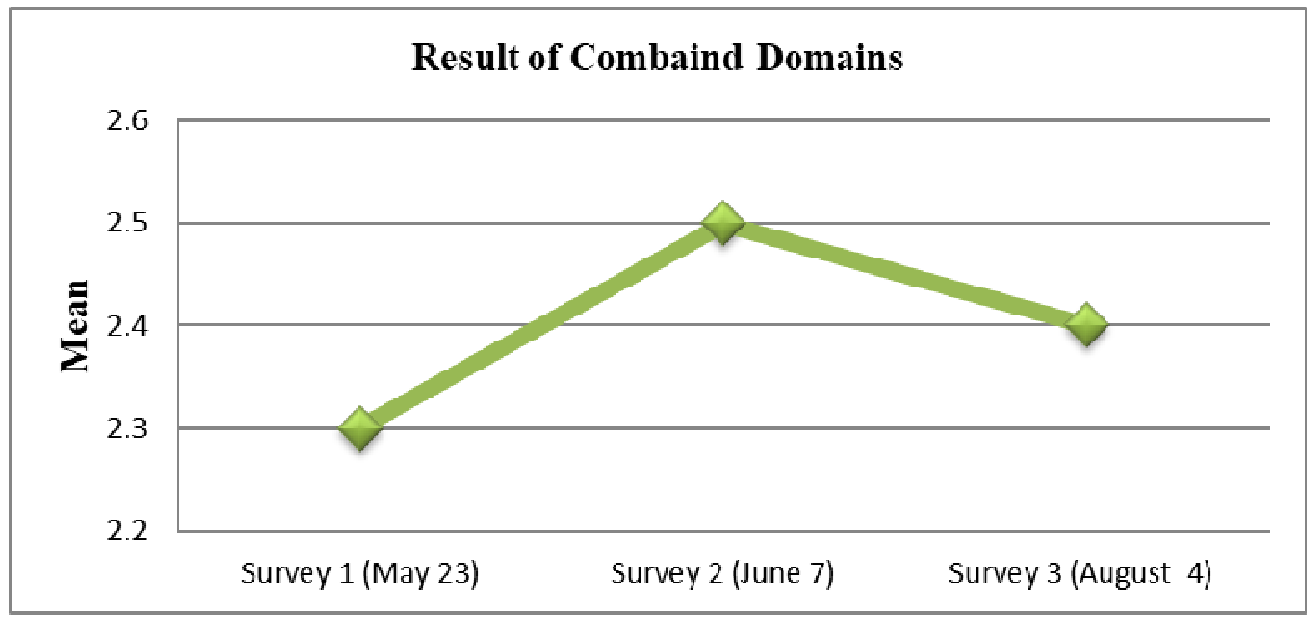

Figure 1. Results of the combined domains on the three Surveys

The data showed that there was improvement in the social skills of children and youth with autism who attended the summer camp program. The time by treatment interaction when all domains were combined together on the three surveys was statistically significant $(F=8.13$. $p$ value $=0.000621)$. The time by treatment 
interaction was statistically significant at the confidence level of $p<.01$ between Survey 1 and Survey 2 . The time by treatment interaction was statistically significant at the confidence level of $p<.05$ between Survey 1 and 3 ; whereas, it was not statistically significant between Survey 2 and Survey 3.

Table 3. ANOVA for Results of the Significance for the Combined Domains

Standard weighted-means analysis

\begin{tabular}{llllll}
\hline ANOVA Summary Correlated Samples k=3 & & & & \\
Source & SS & df & MS & F & P \\
Treatment & 283.65 & 2 & 141.825 & 8.13 & 0.000621 \\
Between groups & & & & & \\
Error & 1360.35 & 78 & 17.4404 & \\
SS/BI & 6273.3 & 39 & & \\
Total & 7917.3 & 119 & & \\
\hline
\end{tabular}

3.1.1.2. Results of significance for each domain. The statistical analysis produced further details about the total score for each domain used in this study. The domains were communication, reciprocity, social cognition, initiation, and perspective taking and self-awareness.

3.1.1.3. Communication domain. The data showed that there was statistically significant improvement in the Communication Domain for children and youth with ASD because of the summer camp intervention. The time by treatment interaction between Survey 1 and Survey 2 was statistically significant $F=4.17, p$ value $=0.019029$. There were no statistically significant differences between Survey 1 and Survey 3, and between Survey 2 and Survey 3.

Table 4. ANOVA for Communication Domain

Standard weighted-means analysis

\begin{tabular}{llllll}
\hline \multicolumn{2}{l}{ ANOVA } & Summary Correlated Samples k=3 & & & \\
Source & SS & df & MS & F & P \\
Treatment & 11.85 & 2 & 5.925 & & 0.019029 \\
Between groups & & & & \\
Error & 110.8167 & 78 & 1.4207 & \\
SS/BI & 258.5333 & 39 & & \\
Total & 381.2 & 119 & & \\
\hline
\end{tabular}

3.1.1.4. Reciprocity domain. The data showed that there was statistically significant improvement in reciprocity skills for children and youth with ASD who received the summer camp intervention. The time by treatment interaction from Survey 1 to Survey 2 was statistically significant $F=3.45, p=0.036668$, but there were no statistically significant differences between the first survey and the third survey and between the second survey and third survey.

Table 5.ANOVA for Reciprocity Domain

\begin{tabular}{|c|c|c|c|c|c|}
\hline \multicolumn{6}{|c|}{ ANOVA Summary Correlated Samples $k=3$} \\
\hline Source & SS & df & MS & $\mathrm{F}$ & $\mathrm{P}$ \\
\hline Treatment & 21.05 & 2 & 10.525 & 3.45 & 0.036668 \\
\hline \multicolumn{6}{|c|}{ Between groups } \\
\hline Error & 237.6167 & 78 & 3.0464 & & \\
\hline $\mathrm{SS} / \mathrm{BI}$ & 447.2583 & 39 & & & \\
\hline Total & 705.925 & 119 & & & \\
\hline \multicolumn{6}{|c|}{$\begin{array}{l}\text { 3.1.1.5. Social cognition domain. The data showed that there were no statistically significant differences in } \\
\text { social cognition skills for children and youth with ASD who received the summer camp intervention. The time } \\
\text { by treatment interaction between Survey } 1 \text { and Survey } 2 \text { was not statistically significant } F=1.27, p=(0.286574) \text {. } \\
\text { Also, there were no statistically significant differences between the second Survey and the third Survey, and } \\
\text { between the first Survey and the third Survey. } \\
\text { Table 6.ANOVA for Social Cognition Domain }\end{array}$} \\
\hline \multicolumn{6}{|c|}{ Standard weighted-means analysis } \\
\hline \multicolumn{6}{|c|}{ ANOVA Summary Correlated Samples $k=3$} \\
\hline Source & SS & $\mathrm{df}$ & MS & $\mathrm{F}$ & $\mathrm{P}$ \\
\hline \multicolumn{6}{|c|}{ Between groups } \\
\hline Error & 100.0667 & 78 & 1.2829 & & \\
\hline $\mathrm{SS} / \mathrm{BI}$ & 134.1333 & 39 & & & \\
\hline Total & 237.4667 & 119 & & & \\
\hline
\end{tabular}


3.1.1.6. Initiation domain. The data showed that there was statistically significant improvement in initiation skills for children and youth with ASD who received the summer camp intervention. The time by treatment interaction between Survey 1 and Survey 2 was statistically significant $F=3.79, \mathrm{p}=0.026864$, but it was not statistically significant between the first survey and the third survey and between the second survey and third survey.

Table 7.ANOVA for Initiation Domain

\begin{tabular}{|c|c|c|c|c|c|}
\hline \multicolumn{6}{|c|}{ Standard weighted-means analysis } \\
\hline \multicolumn{6}{|c|}{ ANOVA Summary Correlated Samples $k=3$} \\
\hline Source & SS & $\mathrm{df}$ & MS & $\mathrm{F}$ & $\mathrm{P}$ \\
\hline Treatment & 3.2667 & 2 & 9.3583 & 3.79 & 0.026864 \\
\hline \multicolumn{6}{|c|}{ Between groups } \\
\hline Error & 100.0667 & 78 & 2.4694 & & \\
\hline $\mathrm{SS} / \mathrm{BI}$ & 670.6583 & 39 & & & \\
\hline Total & 881.9917 & 119 & & & \\
\hline \multicolumn{6}{|c|}{$\begin{array}{l}\text { 3.1.1.7. Perspective taking and self-awareness domain. The data showed that there were no statistically } \\
\text { significant differences in perspective taking and self-awareness skills for children and youth with ASD who } \\
\text { received the summer camp intervention. The time by treatment interaction between Survey } 1 \text { and Survey } 2 \text { was } \\
\text { not statistically significant } F=1.89, p=0.157926 \text {. The change from the first Survey to the second Survey was } \\
\text { not statistically significant. Also, there were no statistically significant differences between the second Survey } \\
\text { and the third Survey, and between the first Survey and the third Survey. } \\
\text { Table 8.ANOVA for Perspective Taking and Self-awarenessDomain }\end{array}$} \\
\hline \multicolumn{6}{|c|}{ Standard weighted-means analysis } \\
\hline \multicolumn{6}{|c|}{ ANOVA Summary Correlated Samples $k=3$} \\
\hline Source & SS & df & MS & $\mathrm{F}$ & $\mathrm{P}$ \\
\hline Treatment & 9.05 & 2 & 4.525 & 1.89 & 0.157926 \\
\hline \multicolumn{6}{|c|}{ Between groups } \\
\hline Error & 186.2833 & 78 & 2.3882 & & \\
\hline $\mathrm{SS} / \mathrm{BI}$ & 480.6667 & 39 & & & \\
\hline Total & 676 & 119 & & & \\
\hline
\end{tabular}

\section{Discussion}

This study investigated the impact of a summer camp program in improving social skills for children and youth with ASD through participation in a variety of specific activities. There was a statistically significant improvement in social skills when all of the domains were combined. When the domains were analyzed separately, three out of five domains were impacted positively. Parents rated progress on the communication subscale, the reciprocity subscale, and the initiation subscale, whereas there were no significant changes on social cognition and perspective taking and self-awareness skills. The time by treatment interaction when all domains were combined together on the three surveys was statistically significant $F=8.13 . p=0.000621$. The time by treatment interaction was statistically significant at the confidence level of $p<.01$ between Survey 1 and Survey 2 , the time by treatment interaction was statistically significant at the confidence level of $\mathrm{p}<.05$ between Survey 1 and 3; whereas, it was not statistically significant between Survey 2 and Survey 3.

The reason for the significant change between Survey 1 and Survey 2 might be because the campers followed directions, and they worked in small groups. Also, counselors and junior counselors had training before participating in the summer camp. Many campers and counselors have had experience, because they participated in past Camp New Amigos. All activities were designed and organized in an appropriate way for participants with ASD. The time for each of the activities was perfect as it did not allow the participants to get bored. The agenda prevented campers from getting frustrated because each camper had more than one opportunity to try every activity. Also, there were daily visual schedules, which helped campers understand what is expected of them thereby reducing occurrences of challenging behaviors. The visual schedules also assisted campers in transitioning independently between the activities in Camp New Amigos.

Camp New Amigos incorporated structured play and non-directive play. Play in structured or non-directive environments helps children and youth with ASD to improve different social skills (Walker, Barry, \& Bader, 2010). Play in structured environments helps children and youth with ASD learn play skills such as sharing, responding to others, taking turns, and interacting with others. Non-directive play provides children and youth with ASD with experiences of language and communication strategies; in this case, by providing campers with a safe environment and various toys, such as puzzles, and symbolic play (Josefi\& Ryan, 2004). Social skills play are importantfor training children with ASD on communicating with others, orhow to act in certain social situations, as well as maintaining meaningful social and emotional relationships ( Mpella, Evaggelinou, Koidou, \&, Tsigilis, 2019). 
The summer camp had many games and activities that helped children and youth with ASD recognizenonverbal cues, or body language, including gestures, signs, and the use of personal space. The summer camp activities included sports, arts and crafts, wall climbing, and horseback riding. These activities helped campers learn to politely ask others to move out of their way, to join their peers in activities, to respond to the greetings of others, and to help others with tasks. Also, these activities helped students to interact with their friends, to engage in give-and-take and turn-taking, and to maintain eye contact during conversations with adult counselors, and with junior counselors.

The data showed statistical significance at $\mathrm{p}<.05$ level between the first survey and the third survey when all domains were analyzed together. The campers maintained the social skills which they developed during the summer camp program The parents also played important roles in maintaining these skills. Parents had a meeting with the counselors and administrators before the summer camp, and everyone worked together to adapt the social skills that campers needed to improve. Also, counselors provided each parent with daily reports about the skills students improved on, and the skills they needed to work on to make progress.

There were no statistically significant changes between the second survey and the third survey or when the first survey was compared with the third survey. The reason might be because the period between the post-survey at the end of camp and the follow-up survey was long, approximately 8 weeks. The summer camp was very short, and there was no school or other interventions during the summer.

The results of this study suggest that there were no statistically significant changes in social cognition skills due to participation in the summer day camp for children and youth with ASD. The counselors and the junior counselors modeled skills for the campers during camp activities. It is possible that socialcognitive skills could be improved for children with higher functioning levels, whereas the summer camp had many campers with low functioning levels and campers who were non-verbal. These factors affected the results negatively.

In order to significantly improve social cognitive skills, children with ASD might need an intensive program with weekly hour-long sessions; which was not possible since the summer camp was limited to one week. Studies indicated that intensive intervention can improve social cognition skills for children and youth with ASD (Bauminger, 2007; Gevers, Clifford, Mager, \& Boer, 2006). Intensive intervention could help children and youth with ASD understand humor, interpersonal relationships, demonstrate improvement in assertiveness, obtaining progress in social cognition skills and social interactions, and self-control.

To improve social cognition skills for campers, specific goals should be developed for the campers, using strategies that could improve social cognition skills by providing activities using speech generating devices. Social cognition could be improved by applying one-on-one therapy that teaches children how to compromise during disagreements with others, interpret the intentions of others, and respond to questions directed at them by others. This would require an increased number of counselors and junior counselors in the summer camp.

The results showed that there were no statistically significant changes in the perspective taking and selfawareness skills during summer camp for children and youth with ASD. The results might be because the summer camp activities did not promote and teach the skills that help campers to make progress in these areas.

Adding specific activities into the camp curriculum could help. Examples of activities that might be added include developing social story activities to increase perspective-taking in social situations and designing comic strip conversations might be helpful to increase the campers' awareness of the thoughts and feelings of others. Providing campers with intensive, daily social thinking programsmay increase their ability to interact with peers and maintain a good relationship with them. Some activities that could be incorporated include activities to help them keep up with the game or understand the rules, maintain an appropriate distance when interacting with peers,speak with an appropriate volume in conversations, talk about or acknowledge the interests of others, and offer assistance to others.

\section{Limitations}

This study is one of very few studies that looked at the importance of a summer camp program in improving social skills for children with ASD. This study had some limitations. The time period for summer day camp was short. Campers only received the interventions for five days, six and a half hours per day for a total of 32.5 hours. Asking parents to complete the survey three times was another limitation. It was difficult for many parents to submit the survey, because they did not have access to a computer. Also, they did not have sufficient skills to use Microsoft Word, and this made it necessary to drive to some of their homes to pick up the survey or to make phone calls to complete the surveys.

The degree of understanding of the questionnaire by parents was another limitation. Some parents did not understand some terms or how they could evaluate these items. This could be due to the limited education of some of the parents. Future studies might address this. The length of time to complete each survey was another limitation. Some parents were working, and they came back late from work, so they felt too tired to fill out the survey three times. Some parents were traveling during the summer and did not have access to their computer.

Bellini (2008) used 49 items, whereas this study used 19 items. The study did not use all the ASSP 
questions and this might have affected the results of the summer camp research. Also, the percent of non-verbal campers could have affected the results. Twenty-two and a half percent $(n=11)$ were reported as non-verbal, with the majority of questions relating to verbal children. The numbers of female campers were limited; parents of only four girls participated in this study. The results may be different if all 75 parents were participated on the research.

Not having control group may allow threats to the internal validity of the study. Examples of internal validity threats are history threats and maturation threats. It may not be the summer camp intervention that caused the improvement in social skills; some other intervening variable could have contributed to the improvement. For example, participation in other programs during the summer might improve social skills for children and youth with ASD. Also, normal maturation or growth happened as part of length of time that passed between the distributions of the surveys.

Generalizing results may be another limitation, because many skills were learned through camp specific activities, which are often not available. Schools and after-school programs should look at structuring a camplike setting to assist in learning social skills in these areas.

\section{Implications for future research}

For future studies, it would be important to see if extending Camp New Amigos to more than one week impacts data results. Future studies could also create a specific survey to use with parents of non-verbal children, which might change the results about the impact of summer camp. It would also be important to study if campers can generalize the skills they obtained during summer camp in different environments and with different people. Generalization might provide children and youth with ASD with more ways to achieve desired outcomes. It would be important for campers to generalize and to maintain the skills they learned in different settings to be successful in their lives. It would be important to study whether the addition of activities support cognition skills and perspective taking and self-awareness, possibly changing results. Adding additional activities that are related to social cognition skills and perspective taking and self-awareness may yield different results. Examples of these activities are social stories, video molding, and comic strips. These activities might improve social skill for low functioning children and youth with ASD, and might work effectively with higher functioning campers as well.

Using a random clinical trial in a future study might be a recommendation for future research. Adding a control group to an experimental group is very important to able to determine the difference between the two groups in gaining or in improving the social skills that were analyzed in this study.

If the same survey was rated by counselors and parents at the same time, there might be more reliability. The most important thing about Bellini instrument is teachers, parents, counselors, or other support personnel can use it easily to evaluate the level of the participants. Evaluating the campers at the same time with different people (counselors, parents, etc.) could make the results stronger and more effective.

Using Evidence Based Practices (EBP) such as video modeling and direct teaching interventions targeting the following skills might change the results: simple and complex motor imitation, parallel play, ball play, taking turns, seeking play partners, partner pretend play, and appropriate use of play stations.

\section{Conclusion}

The prevalence of ASD is in increasing, and children and youth with ASD need different types of interventions to improve their communication and social skills and behavior. Providing different interventions could make children and youth with ASD and their parents feel that they are not alone, and that educators are there to support them and make them feel that they are a part of the community. Intensive summer camp programs will help children and youth with ASD and their parents to be active in their community. Children and youth with ASD were able to demonstrate social skills improvement in the summer camp program and for a short period of time after the camp intervention concluded. This means that using a variety of strategies, activities, and interventions commonly seen in a summer camp program may help children with ASD to be perceived as more socially adept.

\section{Acknowledgment}

We would like to thank parents of children and youth with ASD who participated in this study, by completing the survey three times and providing me with important data.

\section{References}

Bauminger, N. (2007). Brief report: Group social-multimodal intervention for HFASD. Journal of Autism and Developmental Disorders, 37, 1605-1615.

Bellini, S. (2008). Building Social Relationships. Shawnee Mission, KS: Autism Asperger Publishing Company.

Bellini, S., \&Hopf, A. (2007). The development of the autism social skills profile: A preliminary analysis of psychometric properties. Focus on Autism and Other Developmental Disabilities, 22, 80-87. 
Elliott, S. N., Malecki, C. K., \&Demaray, M. K. (2001). New directions in social skills assessment and intervention for elementary and middle school students. Exceptionality, 9, 19-32.

Gevers, C., Clifford, P., Mager, M., \& Boer, F. (2006). Brief report: A theory of mind based social cognition training program for school-aged children with pervasive developmental disorders: An open study of its effectiveness. Journal of Autism and Developmental Disorders, 36(4), 567-571.

Goin, R. P., \& Myers, B. J. (2004). Characteristics of infantile autism: Moving toward earlier detection. Focus on Autism and other Developmental Disabilities, 19(1), 5-12.

Goldstein, S., Naglieri, J.A., Rzepa, S., Williams, K.M. (2012). A national study of autistic symptoms in the general population of school-age children and those diagnosed with autism spectrum disorders. Psychology in Schools, 49(10), 1001-1016.

Goldstein, S. \&Ozonoff, S. (2009). Historical perspective and overview. In S. Goldstein, J.A.

Josefi, O., \& Ryan, V. (2004). Non-directive play therapy for young children with autism: A case study. Clinical Child Psychology and Psychiatry, 9(4), 533-551.

Kanner, L. (1943). Autistic disturbances of affective contact. Nervous Child, 2, 217-250.

Kellman, R. (2010).The autism-thyroid connection.Raphael. The Exceptional Parent, 40(4)p.16.

Kristen-Clark, M., \&Nwokah, E. (2011). Play and learning in summer camps for children with special needs. American Journal of Play, 3, 238-261.

Maenner MJ, Shaw KA, Baio J, et al (2020). Prevalence of Autism Spectrum Disorder Among Children Aged 8 Years - Autism and Developmental Disabilities Monitoring Network, 11 Sites, United States, 2016. MMWR SurveillSumm;69(No. SS-4):1-12.

Morrison, L., Kamps, D., Garcia, J., \& Parker, D. (2001). Peer mediated and monitoring strategies to improve initiations and social skills for students with autism. Journal of Positive Behavior Interventions, 3(4), 237250. Parner, E. T., Baron-Cohen, S., Lauritsen, M. B., Jørgensen, M., Schieve, L. A., Yeargin-Allsopp, M.,\&Obel, C.(2012).Parental age and autism spectrum disorders. Annals of Epidemiology, 22(3), 143150 .

Mpella,M., Evaggelinou, C., Koidou, E.\&, Tsigilis, N. (2019). The Effects of a theatrical play programme on social skills development for young children with autism spectrum disorders. International Jaournal of Special Education, 33(4), 828-845.

Napolioni, V., Lombardi, F., Sacco, R., Curatolo, P., Manzi, B., Alessandrelli, R., Persico, A. M. (2011). Family-based association study of ITGB3 in autism spectrum disorder and its endophenotypes. European Journal of Humamities, 19, 353-359.

Ostryn, C., Wolfe, P.S., \& Rusch, F.R. (2008). A review and analysis of the Picture Exchange Communication System (PECS) for individuals with autism spectrum disorders using a paradigm of communication competence. Research \& Practice for Persons with Severe Disabilities, 33, 13-24.

Schall, C. M., \& McDonough, J. T. (2010). Autism spectrum disorders in adolescence and early adulthood: Characteristics and issues. Journal of Vocational Rehabilitation, 32, 81-88.

Sicile-Kira, C. (2004).Autism spectrum disorders:Thecomplete guideto understanding autism, Asperger's syndrome, pervasive developmental disorder, andother ASDs.A Perigee Book. New York, New York

Sterponi, L. \& Shankey, J. (2013). Rethinking echolalia: Repetition as interactional resource in the communication of a child with autism. Journal of Child Language. http://journals.cambridge.edu/repo_A883Qy0j

Tsai, L. Y. (1998). Pervasive developmental disorders. National dissemination center for children with disabilities, FS20, pp. 1-15

Walker, A. N., Barry, T. D., \& Bader, S. H. (2010). Therapist and parent ratings of changes in adaptive social skills following a summer treatment camp for children with autism spectrum disorders: A preliminary study. Child Care and Youth Forum, 39, 305-322.

Wilczynski, S. M., \& Pollack, E. G. (2009), Setting the standard for autism treatments: National autism center releases groundbreaking report. Exceptional Parent, 39(12) 50-51. 